\title{
Effect of Sal (Shorea robusta) seed meal on growth and carcass quality in broiler
}

\author{
Rahman M $^{1}$, M Ahammed ${ }^{2}$, ME Hossain ${ }^{2}$, MAR Howlider ${ }^{2}$ and AKMA Kabir ${ }^{3} *$
}

${ }^{1}$ Department of Livestock Services, Farmgate, Dhaka-1215, Bangladesh; ${ }^{2}$ Department of Poultry Science, Bangladesh Agricultural University, Mymensingh-2202, Bangladesh; ${ }^{3}$ Department of Animal Science, Bangladesh Agricultural University, Mymensingh-2202, Bangladesh

\begin{abstract}
This study was conducted to investigate the effect of dietary sal (Shorea robusta) seed meal (SSM) on growth performance, carcass characteristics and economic feasibility in broilers. Two hundred day-old, straight-run (Cobb-500) broiler chicks were randomly allocated to five dietary treatments for 42 days feeding trial (40 birds each). Dietary treatments were designed according to SSM supplementation levels, namely control diet (0\% SSM), diets containing 10 and $15 \%$ of un-boiled SSM (USSM), and diets containing 15 and $20 \%$ of boiled SSM (BSSM). At the end of feeding trial, 20 birds (2birds per replication) were subjected for determining the meat yield parameters. Overall weight gain of control and $0 \%$ BSSM 2 group was higher $(p<0.001)$ than that of other groups. Feed consumption was higher in control and 20\% BSSM group where as 15\% USSM group exerted the lowest. Poorest FCR and performance index were showed in the birds of $15 \%$ USSM supplemented group. There were no differences in meat yield parameters among treatments. Total profit per kg live broiler was significantly $(p<0.001)$ higher on diet with $20 \%$ BSSM. The boiling of SSM was effective to reduce the tannin-related depression on the performance of broilers. In conclusion, broilers received diets containing BSSM up to $20 \%$ showed better growth performance along with profitability, and this boiled SSM could be used as an alternative energy source ingredient in broilers having no detrimental effects on performance.
\end{abstract}

Key words: Shorea robusta seed, broiler, growth, meat quality, tannin

Bangladesh Animal Husbandry Association. All rights reserved.

Bang. J. Anim. Sci. 2017. 46 (1): 10-16

\section{Introduction}

Scarcity of cereal grain is one of the problems for economic poultry production. Poultry compete directly with human and other livestock for grain, which constitutes about $50 \%$ of compound feed. Maize is the principal conventional grain used for formulating poultry diets in Bangladesh and worldwide. Considering the expansion of poultry industry, the availability of maize is still not satisfactory. The price of different feed ingredients is showing an upward trend, because there is a high demand for essential items. Therefore, poultry rearing practices have become more challenging. Thus the higher cost of conventional feed ingredients has made economic poultry production difficult in Bangladesh. So, potentiality of alternative ingredients is to be explored.
However, to reduce the cost of feeding various attempts have been made by poultry nutritionist to substitute cereal grains partly or wholly by agricultural, industrial and forest by-products. Sal (Shorea robusta) seed is a forest by-product available in huge quantity in the forest areas of Bangladesh. It is of potential interest in animal nutrition because the sal seed meal (SSM) obtained after extraction of oil from the seed is rich in carbohydrate ( $\mathrm{CHO})$, non-available $\mathrm{CHO}$ fractions, and also contains crude protein (CP) and ether extract (EE), similar to that of wheat (Zombade et al., 1979). Nayak et al. (1967) showed that SSM could replace maize up to $5 \%$ of the diet without deleterious effects on growth rate of chicks. Several investigators have examined the proximate components of SSM. They (Zombade et al., 1979) observed that SSM contains $98 \mathrm{~g} \mathrm{CP}, 22 \mathrm{~g} \mathrm{EE}$ and $450 \mathrm{~g}$ available $\mathrm{CHO}$ and $117 \mathrm{~g}$ tannins and $2671.43 \mathrm{kcal}$ ME per $\mathrm{kg}$. Banerjee (1998) showed that SSM contains about

Corresponding author: ahsankabiras@bau.edu.bd 
80 to $90 \mathrm{~g} \mathrm{CP}, 120$ to $160 \mathrm{~g} \mathrm{EE}, 20$ to $30 \mathrm{~g}$ fibre and $850 \mathrm{~g}$ NFE per $\mathrm{kg}$. Tannin, a polyphenolic toxin compound is found in sal seed and it can be inactivated by different physico-chemical process (Banerjee, 1989).From the above information, it is clear that sal seed (Shorea robusta) may be an alternative to replace the conventional cereal grains for poultry diets. Therefore, the purpose of the present study was undertaken to exploit the possibilities to use SSM as an alternative energy source ingredient in broiler diets.

\section{Materials and Methods}

\section{Preparation of USSM and BSSM}

The sal seed were collected from Modhupor sal forest, Tangail, Bangladesh. The collected sal seeds were sun dried and de-hulled manually until its maximum moisture was lost up to $15 \%$. The de-hulled seeds were boiled at $100^{\circ} \mathrm{C}$ for 35 minutes and sun dried. Both boiled (BSSM) and un-boiled (USSM) sal seeds were ground through a $1.0 \mathrm{~mm}$ mesh screen, and then stored to the polythene bags prior to the use in the diets. The proximate composition, total tannin content of USSM and BSSM were analyzed according to the AOAC (2006) and Price et al. (1978) methods, respectively. Metabolizable energy of USSM and BSSM at different dietary levels was estimated using the formula suggested by Wiseman, (1987) (Table 1).

\section{Birds, Diets and Sampling}

A total of 200 straight-run broilers (Cobb-500) were housed in floor barn bedded with rice husk. Birds were randomly allocated to five dietary treatments for 42 days feeding trial. Each treatment had two replicate pens with 20 birds in each pen. Different levels of SSM ( $0 \%$ as control, 10 and $15 \%$ of USSM, and 15 and $20 \%$ of BSSM with diet, respectively) were supplemented to make five experimental diets. Two diets were used for starter phase (day 1 to day21) and finisher phase (day22 to day42) to meet the NRC (1994) nutrients requirement for broilers. The diets were formulated using locally available feed ingredients as shown in Table 2 and 3. Feed and water were supplied ad libitum. During the feeding trial, feed intake and body weight (BW) were measured weekly. The room temperature was adjusted at $33^{\circ} \mathrm{C}$ for the $\mathrm{d} 1$ and then gradually reduced to $22 \pm 1^{\circ} \mathrm{C}$, then maintained the temperature until the end of feeding trial.

\section{Data collection}

Body weight (BW) and feed intake (FI) were measured by replication on a weekly basis and used to calculate feed conversion ratio (FCR)and weekly live weight gain. Mortality of birds was calculated for each replication daily when death occurred. Performance index was also measured to observe the performance of broilers. On day 42 , two birds per replication (one male and one female) were randomly selected and slaughtered for meat yield parameters. Immediately after slaughterblood, feathers, different visceral organs, abdominal fat and meat of different parts were excised, weighed and expressed as relative weight in grams (g) per $100 \mathrm{~g}$ of body weight. At the end of feeding trial cost benefit analysis was performed considering between all costs and sale price of live broilers.

Table 1. Proximate composition and tannin content of Sal Seed Meal (as fed basis)

\begin{tabular}{lrr}
\hline Nutrient composition & USSM* (\%) & BSSM** (\%) \\
\hline Moisture & 8.12 & 9.42 \\
Crude protein & 9.25 & 10.35 \\
Ether extract & 13.95 & 11.26 \\
Crude fiber & 6.32 & 4.35 \\
Ash & 3.14 & 3.83 \\
Nitrogen free extract & 50.76 & 55.15 \\
${ }^{1}$ Tannin & 8.46 & 5.64 \\
${ }^{2}$ Metabolizable energy $(\mathrm{kcal} / \mathrm{kg})$ & 4026 & 4021 \\
\hline
\end{tabular}

*USSM, un-boiled sal seed meal; **BSSM,boiled sal seed meal. ${ }^{1}$ According to the procedure described by price et al. in 1978. ${ }^{2}$ Using the formula suggested by Wiseman, 1987. 


\section{Statistical analysis}

All calculated data collected were statistically analyzed using a one-way analysis of variance. The means were subjected to the test of significance by Duncan Multiple Range Test using SPSS software (SPSS, 2010). Pen was considered as the experimental unit for all statistical analyses. The dressing yield parameters were for 2 (sex) $x 5$ (diets) factorial experiment in a CRD. Significant differences among mean values were presented as $P$-values and superscripts.

\section{Results}

\section{Nutrient composition of USSM and BSSM}

The proximate composition and tannin contents of un-boiled and boiled SSM are presented in Table 3. Since the tannin concentration was partially eliminated by heat treatment from dried sal seed, the level of tannin decreased by $33.3 \%$. The energy content of both forms of SSM was higher than that of any other conventional grain based energy ingredients in poultry diet.

\section{Growth performance}

The live weight, feed consumption, feed conversion and performance indices fed on different levels of USSM and BSSM diet is shown in Table 4. During the experimental period, all of the production-related parameters, i.e. daily weight gain, feed intake, feed: gain ratio and performance index were affected by the dietary treatments. The body weight gain of broilers fed $20 \%$ BSSM group was higher than the other SSM groups. Increase of broiler body weight gain by dietary 20\% BSSM group showed better response $(1422 \mathrm{~g})$, but slight decrease occurredwhen compared with the control group (1433g). Also, similar response appeared on feed intake according to the same level(20\%) of dietary BSSM (Table 4). No statistical differences in feed conversion ratio and performance indexbetween the dietary BSSM treatments and control group were pronounced. However, both two parameters (FCR and performance index) showed worst response in un-boiled SSM groups. There were no significant $(p>0.05)$ differences in mortality among the dietary treatments. Although, dietary BSSM groups found no mortality whereas birds of control (2\%) and USSM groups (4 and $2 \%$ ) died in early rearing period.

\section{Economic feasibility}

Total profit per $\mathrm{kg}$ live broiler on different diets is presented in Figure 1. Profit was significantly $(p<0.001)$ highest on $20 \%$ BSSM followed by $0 \%$ SSM, $15 \%$ BSSM, $10 \%$ USSM and $15 \%$ USSM groups respectively. However, except feed cost all other costs for production were same among different dietary groups.

Table 2. Ingredient and nutrient composition of starter diets (\%)

\begin{tabular}{lrrrrr}
\hline \multirow{2}{*}{ Ingredients } & \multicolumn{5}{c}{ Dietary Levels of SSM } \\
\cline { 2 - 6 } & Control & $\mathbf{1 0 \%}$ USSM* & $\mathbf{1 5 \%}$ USSM & $\mathbf{1 5 \%}$ BSSM** & $\mathbf{2 0 \%}$ BSSM \\
\hline Maize & 62.0 & 52.0 & 47.0 & 47.0 & 42.0 \\
Sal seem meal & - & 10.0 & 15.0 & 15.0 & 20.0 \\
Soyabean meal & 15.5 & 15.5 & 15.5 & 15.5 & 15.5 \\
Rice polish & 10.5 & 10.5 & 10.5 & 10.5 & 10.5 \\
Protein concentrate & 5.0 & 5.0 & 5.0 & 5.0 & 5.0 \\
Meat and bone meal & 5.5 & 5.5 & 5.5 & 5.5 & 5.5 \\
Soyabean oil & 1.0 & 1.0 & 1.0 & 1.0 & 1.0 \\
Salt & 0.5 & 0.5 & 0.5 & 0.5 & 0.5 \\
Vit-min. Premix & 0.25 & 0.25 & 0.25 & 0.25 & 0.25 \\
Chemical composition & & & & \\
$\quad$ ME (kcal/kg) & 3065.0 & 3045.3 & 3040.4 & 3055.5 & 3062.6 \\
Crude protein (\%) & 22.75 & 22.70 & 22.55 & 22.65 & 22.65 \\
Calcium (\%) & 1.30 & 1.25 & 1.27 & 1.30 & 1.34 \\
Lysine (\%) & 1.25 & 1.29 & 1.26 & 1.20 & 1.30 \\
Methionine (\%) & 0.50 & 0.52 & 0.50 & 0.55 & 0.54 \\
\hline
\end{tabular}

*USSM, un-boiled sal seed meal; **BSSM=boiled sal seed meal. ${ }^{1}$ Provided the followings per $\mathrm{kg}$ of diet:Vit $\mathrm{A}$, 12000IU;Vit $D_{3}, 3000 I U ; V i t ~ E, 40 m g ; V i t ~ K_{3}, 2.4 \mathrm{mg} ;$ Vit $B_{1}, 1.2 \mathrm{mg} ;$ Vit $B_{2}, 5 \mathrm{mg} ;$ Vit $B_{6}, 3 \mathrm{mg} ;$ Vit $B_{12}, 0.02 \mathrm{mg}$; Niacin, 40mg;Panthothenic acid, 10mg;Folic acid, $0.5 \mathrm{mg} ;$ Biotin, $0.07 \mathrm{mg} ; \mathrm{Mn}, 72 \mathrm{mg} ; \mathrm{Fe}, 48 \mathrm{mg} ; \mathrm{Cu}, 5 \mathrm{mg} ; \mathrm{Zn}, 60 \mathrm{mg}$; Se, $0.18 \mathrm{mg} \mathrm{I}, 1 \mathrm{mg}$. 


\section{Meat yield parameters}

The meat yield parameters of control and different SSM dietary groups are given in Table 5. Sex and interaction of sex and diet did not significantly $(p>0.05)$ affect meat yields parameter. Drumstick meat weight $(\%)$, breast meat weight (\%), dressed weight $(\%)$, dark meat weight (\%), total meat (\%) were noted tended to be highest in broilers fed $20 \%$ BSSM diet and it was also similar with control diet followed by $10 \%$ USSM and $15 \%$ USSM diets. Abdominal fat (\%) was however; highest in females than in males on the birds of all groups and it appeared highest on $20 \%$ BSSM group.

Table 3. Ingredients and nutrient composition of finisher diets (\%)

\begin{tabular}{|c|c|c|c|c|c|}
\hline \multirow{2}{*}{ Items } & \multicolumn{5}{|c|}{ Dietary Levels of SSM } \\
\hline & Control & $10 \%$ USSM* & $15 \%$ USSM & $15 \%$ BSSM** & $20 \%$ BSSM \\
\hline Maize & 60.0 & 50.0 & 45.0 & 45.0 & 40.0 \\
\hline Soybean meal & 17.5 & 17.5 & 17.5 & 17.5 & 17.5 \\
\hline Rice polish & 14.0 & 14.0 & 14.0 & 14.0 & 14.0 \\
\hline Protein concentrate & 5.0 & 5.0 & 5.0 & 5.0 & 5.0 \\
\hline Soybean oil & 1.0 & 1.0 & 1.0 & 1.0 & 1.0 \\
\hline Salt & 0.5 & 0.5 & 0.5 & 0.5 & 0.5 \\
\hline Vit-min. Premix ${ }^{1}$ & 0.25 & 0.25 & 0.25 & 0.25 & 0.25 \\
\hline \multicolumn{6}{|l|}{ Chemical composition } \\
\hline ME (kcal/kg) & 3165.0 & 3167.3 & 3155.4 & 3155.5 & 3162.6 \\
\hline Methionine (\%) & 0.50 & 0.52 & 0.50 & 0.52 & 0.54 \\
\hline
\end{tabular}

*USSM, un-boiled sal seed meal; **BSSM, boiled sal seed meal. ${ }^{1}$ Provided the followings per $\mathrm{kg}$ of $\operatorname{diet}$ :Vit $\mathrm{A}$ 12000IU;Vit $\mathrm{D}_{3}$, 3000IU;Vit E, 40mg;Vit $\mathrm{K}_{3}, 2.4 \mathrm{mg}$;Vit $\mathrm{B}_{1}, 1.2 \mathrm{mg}$;Vit $\mathrm{B}_{2}, 5 \mathrm{mg}$;Vit $\mathrm{B}_{6}, 3 \mathrm{mg}$;Vit $\mathrm{B}_{12}, 0.02 \mathrm{mg}$; Niacin, 40mg; Panthothenic acid, 10mg;Folic acid, $0.5 \mathrm{mg}$; Biotin, $0.07 \mathrm{mg} ; \mathrm{Mn}, 72 \mathrm{mg}$; Fe, 48mg; Cu, 5mg; Zn, 60mg; Se, $0.18 \mathrm{mg} ; \mathrm{I}, 1 \mathrm{mg}$.

Table 4. Effect of different levels of dietary un-boiled (USSM) and boiled (BSSM) sal seed meal on growth performance of broiler chicks

\begin{tabular}{|c|c|c|c|c|c|c|c|}
\hline \multirow[b]{2}{*}{ Parameters } & \multicolumn{5}{|c|}{ Dietary Levels of SSM } & \multirow[b]{2}{*}{ SEM } & \multirow{2}{*}{$\begin{array}{c}\text { P- } \\
\text { values }\end{array}$} \\
\hline & 0\% SSM & 10\%USSM* & $15 \%$ USSM & 15\%BSSM** & 20\%BSSM & & \\
\hline Initial BW (g) & 44.6 & 44.8 & 44.3 & 44.2 & 44.5 & 0.02 & NS \\
\hline \multicolumn{8}{|l|}{ Overall (1 - 42d) } \\
\hline Wt. Gain (g/bird) & $1433^{a}$ & $1229^{c}$ & $1198^{d}$ & $1391^{b}$ & $1422^{a}$ & 26.97 & $* *$ \\
\hline $\mathrm{FCR}(\mathrm{FI} / \mathrm{G})$ & $1.87^{\mathrm{c}}$ & $2.01^{b}$ & $2.41^{a}$ & $1.82^{\mathrm{c}}$ & $1.82^{\mathrm{c}}$ & 0.08 & $* *$ \\
\hline *PI (\%) & $76.51^{a}$ & $61.20^{b}$ & $49.62^{c}$ & $76.27^{a}$ & $77.93^{a}$ & 3.28 & $* *$ \\
\hline Mortality (\%) & 2 & 4 & 2 & 0 & 0 & 0.56 & NS \\
\hline
\end{tabular}

*USSM, un-boiled sal seed meal; **BSSM=boiled sal seed meal. ${ }^{a-c}$ Means in the same row with different superscript differ significantly. FI, Feed Intake; FCR, Feed Conversion Ratio; G, Gain; PI, Performance Index(Live wt.in kg/FCR). NS, Not significant, $*(P<0.05)$; $* * P<0.01$; 
Rahman et al. (2017) Bang. J. Anim. Sci. 46 (1):10-16

\section{Discussion}

\section{Chemical composition of Sal seed meal}

The estimated ME of SSM (4026 kcal/ $\mathrm{kg}$ ) in present study was higher than that of Zombadeet al. (1979) who found the ME content of SSM was $2671.43 \mathrm{kcal} / \mathrm{kg}$. Pandaet al. (1975) also determined the ME value of SSM and sal oil meal (SOM) per their bio-assey. They found 2718.00 and $2653 \mathrm{kcal} / \mathrm{kg}$ respectively, first SSM and SOM which was less than that estimated in current investigation. It really made a great difference in ME content of SSM between the present study and the research conducted by Sutradhar (1990). The obtained CP content in BSSM $(9.42 \%)$ was very close to the findings of Paul et al. (1972) and Zombadeet al. (1979) who found $9.74 \%$ and $9.8 \%$ of CP in SSM respectively. Banerjee (1998)and Kaduskaret al, (1981) also showed that SSM contained about $8-9 \%$ and $10.1 \% \mathrm{CP}$ respectively which was similar to the present study.

\section{Growth performance}

Similar live weight was observed on control and $20 \%$ BSSM diet but the significant $(p<0.05)$ lowered live weight was found on $10 \%$ USSM and $15 \%$ USSM diets.It may be due to the tannin content of SSM which at this level showed to give retarded growth rate of broilers. This result also contradicts with the result of Tarequeand Hayee (1980) who did not found any harmful effect on $15 \%$ USSM diet. Generally, the tannin increases with the increased levels of dietary SSM. This finding is also supported by the observation of Vohra et at. (1966) and Konwaret al. (1987). Lack of deleterious effect on 20\% BSSM in comparison with control diet coincide with the report of Saxena (1971) who found $20 \%$ inclusion level of SSM did not depress the growth of chicks.In our study, it has been revealed that the feed consumption was found to be apparently highest for broilers on $0 \%$ SSM diet, than $15 \%$ USSM diet. It was understood that the reason for fluctuation in feed consumption might be variation in tannin content and astringent taste on different level of SSM diet. This result is supported by Gupta and Haslam (1980) who's reported that feed intake was stimulated due to slight astringent taste.

Table 5. Effect of dietary levels (D) of un-boiled (USSM) and boiled (BSSM) sal seed meal and sex (S) on the meat yield parameters of broilers

\begin{tabular}{|c|c|c|c|c|c|c|c|c|c|}
\hline \multirow{2}{*}{ Parameters } & \multirow{2}{*}{$\begin{array}{l}\text { Sex } \\
(\mathbf{S})\end{array}$} & \multicolumn{5}{|c|}{ Dietary Levels of SSM (\%) } & \multicolumn{3}{|c|}{$\begin{array}{c}\text { LSD (SED) and } \\
\text { Level of significance }^{+}\end{array}$} \\
\hline & & $\begin{array}{l}0 \% \\
\text { SSM } \\
\end{array}$ & $10 \%$ USSM $^{1}$ & $\begin{array}{l}15 \% \\
\text { USSM }\end{array}$ & $\begin{array}{c}15 \% \\
\text { BSSM }^{2} \\
\end{array}$ & $\begin{array}{l}20 \% \\
\text { BSSM }\end{array}$ & $\mathbf{s}$ & D & $S \times D$ \\
\hline \multirow{3}{*}{$\begin{array}{l}\text { Live weight } \\
\text { (g) }\end{array}$} & $M$ & 1455.44 & 1242.83 & 1225.33 & 1409.27 & 1458.79 & $* * *$ & $* * *$ & NS \\
\hline & $\mathrm{F}$ & 1411.35 & 1216.28 & 1171.35 & 1374.06 & 1385.59 & 9.22 & 14.25 & (18.03) \\
\hline & Mean & 1433.39 & 1229.55 & 1198.36 & 1391.67 & 1422.19 & & & \\
\hline \multirow{3}{*}{$\begin{array}{l}\text { Abdominal } \\
\text { fat }(\%)\end{array}$} & M & 2.13 & 2.02 & 1.73 & 2.11 & 2.11 & $* *$ & $* * *$ & NS \\
\hline & $\mathrm{F}$ & 2.24 & 2.10 & 1.87 & 2.13 & 2.31 & 0.25 & 0.32 & $(0.07)$ \\
\hline & Mean & 2.18 & 2.06 & 1.80 & 2.12 & 2.21 & & & \\
\hline \multirow{3}{*}{$\begin{array}{l}\text { Drumstick } \\
\text { meatwt. (\%) }\end{array}$} & M & 7.31 & 6.55 & 6.21 & 7.20 & 7.24 & NS & $* * *$ & NS \\
\hline & $\mathrm{F}$ & 6.51 & 6.11 & 5.69 & 6.67 & 6.83 & $(1.21)$ & 0.94 & $(0.37)$ \\
\hline & Mean & 6.91 & 6.33 & 5.95 & 6.93 & 7.03 & & & \\
\hline \multirow{3}{*}{$\begin{array}{l}\text { Breast meat } \\
\text { weight (\%) }\end{array}$} & M & 11.13 & 9.66 & 8.44 & 10.29 & 12.26 & NS & $* * *$ & NS \\
\hline & $\mathrm{F}$ & 10.26 & 8.98 & 7.85 & 10.00 & 11.14 & $(1.59)$ & 2.70 & (1.04) \\
\hline & Mean & 10.69 & 9.32 & 8.14 & 10.15 & 11.70 & & & \\
\hline \multirow{3}{*}{$\begin{array}{l}\text { Thigh meat } \\
\text { weight }(\%)\end{array}$} & M & 10.31 & 8.31 & 8.49 & 10.14 & 10.18 & NS & $* * *$ & \\
\hline & $\mathrm{F}$ & 9.92 & 7.80 & 6.99 & 9.10 & 9.18 & $(1.98)$ & 2.13 & $(0.90)$ \\
\hline & Mean & 10.11 & 8.05 & 7.74 & 9.62 & 9.68 & & & \\
\hline \multirow{3}{*}{$\begin{array}{l}\text { Dressed } \\
\text { weight }(\%)\end{array}$} & M & 68.22 & 64.98 & 63.86 & 67.71 & 70.00 & NS & $* * *$ & NS \\
\hline & $\mathrm{F}$ & 67.98 & 65.07 & 63.19 & 67.23 & 69.09 & $(0.71)$ & 4.97 & (1.09) \\
\hline & Mean & 68.10 & 64.71 & 63.52 & 67.47 & 69.55 & & & \\
\hline \multirow{3}{*}{$\begin{array}{l}\text { Total meat } \\
\text { weight (\%) }\end{array}$} & M & 32.61 & 28.44 & 27.26 & 30.83 & 33.97 & NS & $* * *$ & NS \\
\hline & $\mathrm{F}$ & 30.50 & 27.78 & 26.62 & 28.86 & 31.38 & $(0.89)$ & 3.56 & $(0.83)$ \\
\hline & Mean & 31.55 & 28.12 & 26.93 & 29.84 & 32.68 & & & \\
\hline
\end{tabular}

${ }^{1}$ USSM, un-boiled sal seed meal; ${ }^{2}$ BSSM, boiled sal seed meal. M, Male; F, Female; NS, Not significant, $*(\mathrm{P}<0.05)$; ** $\mathrm{P}<0.01 ; * * * \mathrm{P}<0.001$. 
In contrast, SSM and seeds containing high levels of hydrolysable tannins resulted in increased feed intake in chicks (Zombadeet al., 1979). It seemed that boiling correct the tannin content of seed and improves the taste and intake. These present investigation coincide Banerjee (1998) who showed the processing of sal seed increased palatability and intake.The present study showed that feed efficiency influenced significantly $(p<0.01)$ among different SSM diets. But, the seasons of fluctuation in feed conversion on different diets were unknown. Since, control diet did not contain SSM. So, enzymatic activity and nutrient availability was not hampered on the digestive tract of birds. On the other hand, different levels of SSM (boiled/un-boiled) might have increased dietary tannin at various (polyphenols) levels and it possibly created inhibitory effects on the formation of active enzymes (Oh et al., 1980) that might subsequently affected feed conversion. This result is in agreement with the findings of Mahmood and Smithard (1993) who found a large reduction in the digestion of amino acids, starch and lipid due of inactivation of digestive enzymes by the formation of tannin-enzyme complex in the digestive tract of chicken.

The result of the present study was consistent with the finding of Kaduskaret al. (1981) who observed the high inclusion level of SSM in the diet retarded the feed utilization due the presence of tannin and some other unknown incriminating factors. This finding agreed with Zombadeet al. (1979). They found poor feed conversion at more than $5 \%$ SSM in diet. This report also coincides with the observation of Vohra et al. (1966) who found the feed conversion of chicks decreased as the level of tannic acid increased in their diets. But, Nayaket al. (1967) reported that when SSM replaced maize by $5 \%$, no sign of deficiency was seen and efficiency was better. But, at $20 \%$ BSSM increased the feed efficiency possibly due to reduction of tannic acid from the seed through treatment (boiling). This finding were supported by Panda and Pradhan (1967) who showed that boiling of sal seed for half an hour removed $60 \%$ tannic acid.The mortality was found only the birds fed diets on control and USSM groups. However, no disease problems were appeared in the flock but mortality might be noticed due to nutritional and brooding management problems. In this study, it seems to be clear that higher level of SSM in diet not the causes of mortality.

Cost benefit analysis observed that, highest profit per $\mathrm{kg}$ live broiler was encountered on 20\%BSSM followed by control, 10\%USSM and 15\%USSM diets respectively (Figure 1).In 20\% BSSM diet, conventional energy ingredient was replaced by SSM; for this, the feed cost for production per $\mathrm{kg}$ of broiler was lowest.

Figure 1. Total profit (Taka/Kg) of live broiler on different dietary levels fed un-boiled and boiled sal seed meal

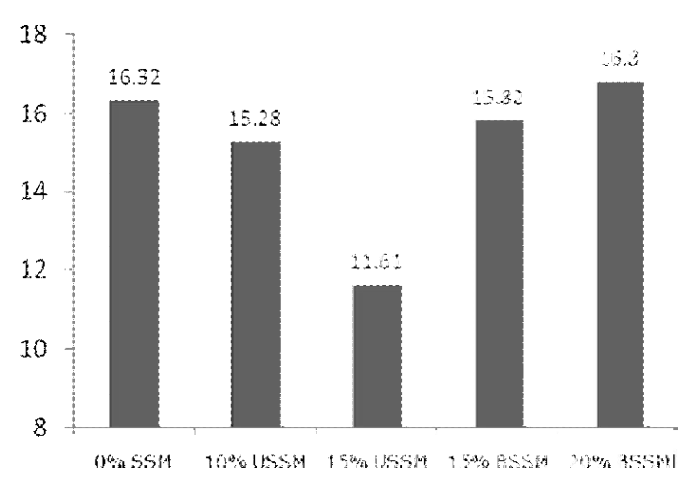

\section{Meat yield parameters}

Sex and interaction of sex and diet had similar $(p<0.05)$ effect on dressing parameters (Table $5)$. The dressed weight percentage was highest on $20 \%$ BSSM intermediate on control and lowest on $15 \%$ USSM. Abdominal fat had significant $(p<0.05)$ effect on sex, female had higher fat percentage than male and it was highest on control and lowest on $15 \%$ USSM. Abdominal fat is higher in female than male is supported by Howlider and Rose (1987).

\section{Conclusion}

In this study, the proximate composition of SSM seems to be more or less similar to that of maize. Processed dietary SSM as high as $20 \%$ was able to not only improve weight gain, feed intake and FCR but can reduce the feed cost for commercial broiler production. It is therefore concluded that, 
Rahman et al. (2017) Bang. J. Anim. Sci. 46 (1):10-16

SSM could be recommended as an alternative energy ingredient for broiler production, where the $20 \%$ BSSM diet could be the appropriate level without any harmful effect. Limited research works have been conducted to use sal seed as poultry feed ingredient, which are not sufficient

\section{References}

AOAC (2006). Official Methods of Analysis of AOAC International. Association of Official Analytical Chemists. 18th edition (Ed itor: William Horwitz, George W. Latimer), Gaithersburg, USA.

Banerjee GC (1989). Poultry. Oxford and IBH Publishing Co. Pvt. Ltd. New Delhi, India.

Banerjee GC (1998). Feeds and Principles of Animal Nutrition. Oxford and IBH Publishing Co. Pvt. Ltd. New Delhi, India.

Gupta RK and E Halam (1980). Vegetable tanninsstructure and biosynthesis. In polyphenols in cereals and legumes (symposium 1979), pp 15-24. Int. Dev. Res. Center, Ottwa.

Howlider MAR and SP Rose (1987). Temperature and the growth of broilers. World's Poult. Sci. J., 43:228-237.

Kaduskar MR, SP Netke and GN Kolte (1981). Effects of high inclusion rates of sal seed (Shorearobusta) meal in the diet of chicks. Brit. Poult. Sci., 22: 503-509.

Konwar BK,A Das andHF Ahmed (1987). Effect of feeding decaffeinated tea waste (Camellia assamica) on broiler. Poult Adviser,20:43.

Mahmood S and R Smithard (1993). A comparison of effects of body weight and feed intake on digestion in broiler cockerels with effects of tannins. Brit. J. Nutri., 70:701-709.

Nayak NC, SB Tripathy and KM Mohanty (1967). Use of decorticated sal seed (Shorearobusta) as poultry feed - A preliminary trial. Indian Vet.J., 44:706-711.

NRC (1994). Nutrient Requirements of poultry. $9^{\text {th }}$ Edn. National Academy Press, Washington, DC.

Oh HI, JE Hoff, GS Armstrong and LA Haff (1980). Hydrophobic interaction in tannin-protein complexes. J. Agric. Food Chem., 28:394-398. to draw meaningful conclusion and recommendation. However, further studies are needed to explain how the SSM is able to improve the growth parameters of broilers.

Panda NC and SC Pradhan (1967). Chemical composition of sal(Shorearobusta) fruits. Indian Vet. J., 44:62-64.

Panda NC, A Mitro, S Kedary and SN Parichha (1975). Sal seed and sal oil meal as cereal ubstitute in starter mash. Indian. Vet. J., 52:186-194.

Paul AK, SN Sengupta, GB Mondal and SK Sarker (1972). Effect of feeding of sal seed cake on chicks. Indian. J. Anim. Sci., 42:1061-1065.

Price ML, SV Scoyoc and LG Butler (1978). A critical evaluation of the vanillin reaction as an assay for tannin in sorghum grain. J. Agric. Food Chem. 26:214-1218.

Saxena HC (1971). Effect of feeding sal (Shorearobusta) seed and sal oil meal to chicks. Indian Poult. Rev., 3:5.

SPSS (2010). Integrated Student Version. 18th Ed 10: 0132151715 Prentice Hall Upper Saddle River; NJ, USA.

Sutradhar P (1990). Utilization of spent tea dust as a feed ingredient in broiler ration. M.Sc. Thesis, Bangladesh Agricultural University, Mymensingh.

Tareque AMM and A Hayee (1980). Utilization of sal seed (Shorearobusta) as poultry feed in Bangladesh. Bangladesh Vet. J., 14:29-34.

Vohra P, FH Kratzer MA Joslyn (1966). The growth depressing and toxic effects of tannins to chicks. Poult. Sci., 45:135-142.

Wiseman J (1987). Feeding of non-ruminant livestock, Butterworths, London, pp: 10. (Translated Version)

Zombade SS, GN Lodhi and JS Ichhponani (1979). The nutritional value of sal seed (Shorearobusta) meal for growing chicks. Brit. Poult. Sci., 20: 433-438. 